SCHOLARONE $^{m}$

Manuscripts
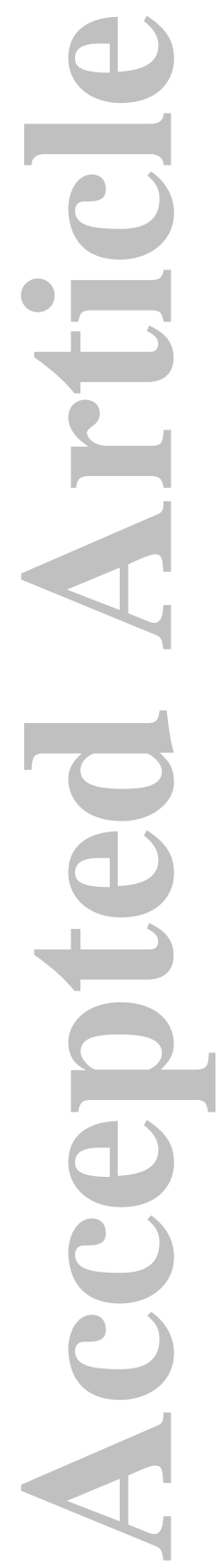

This is the author manuscript accepted for publication and has undergone full peer review but has not been through the copyediting, typesetting, pagination and proofreading process, which may lead to differences between this version and the Version record. Please cite this article as doi:10.1002/ acr.22982.

This article is protected by copyright. All rights reserved. 


\title{
Predictors of Back Pain in Middle Aged Women: Data from the Australian Longitudinal Study on Women's Health
} \\ ${ }^{1}$ Department of Epidemiology and Preventive Medicine, School of Public Health and Preventive Medicine, \\ Monash University, Melbourne, Victoria 3004, Australia \\ ${ }^{2}$ School of Human Movement and Nutrition Studies, University of Queensland, St. Lucia, Queensland, \\ Australia

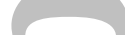 \\ ${ }^{3}$ Monash Centre for Health Research and Implementation, School of Public Health and Preventive \\ Medicine, Monash University, Melbourne, Victoria, Australia \\ ${ }^{4}$ Diabetes and Vascular Medicine Unit, Monash Health, Clayton 3168, Australia \\ Address all correspondence and request for reprints to: \\ Professor Flavia Cicuttini \\ Department of Epidemiology and Preventive Medicine, School of Public Health and \\ Preventive Medicine, Monash University, Alfred Hospital, Melbourne 3004, VIC, Australia
}

John Wiley \& Sons, Inc.

This article is protected by copyright. All rights reserved. 
Telephone: +61399030555

Fax: +61 399030556

Email:flavia.cicuttini@monash.edu
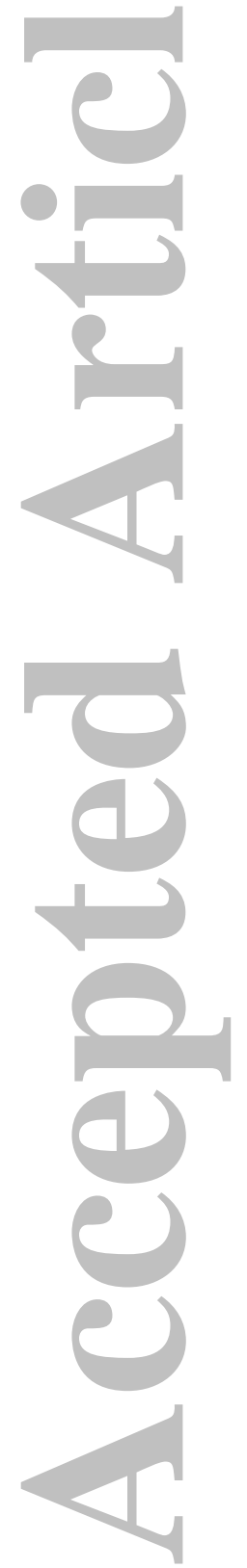

John Wiley \& Sons, Inc.

This article is protected by copyright. All rights reserved. 


\section{Key words}

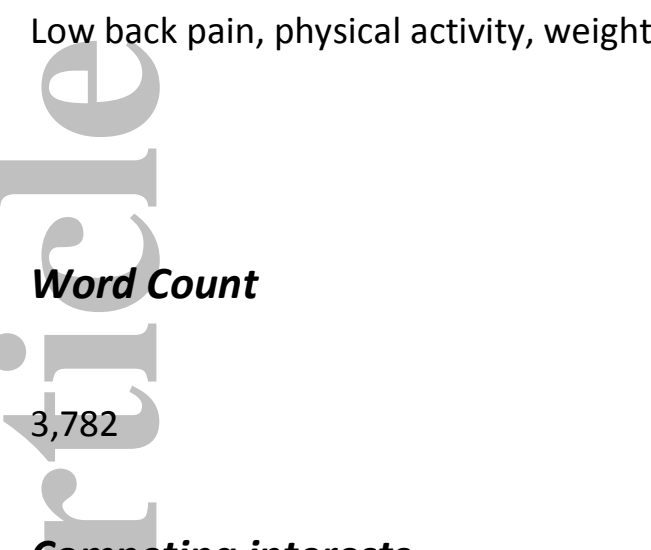

\section{Competing interests}

The authors declare that they have no competing interests.

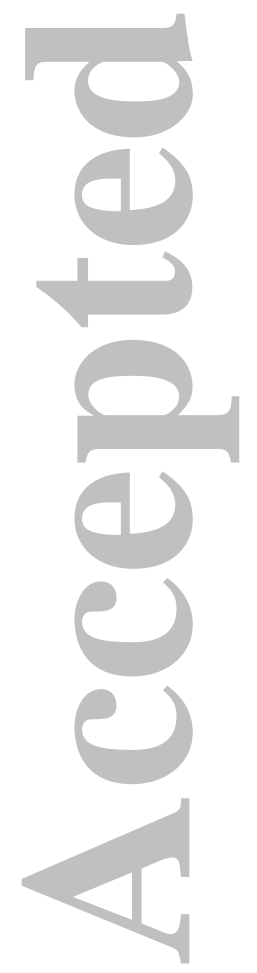

John Wiley \& Sons, Inc.

This article is protected by copyright. All rights reserved. 


\section{Abstract}

Background: Back pain causes greater disability worldwide than any other condition, with women more likely to suffer from back pain than men. Our aim was to identify modifiable risk factors for back pain in middle-aged women.

Methods: Women born between 1946 and 1951 were randomly selected from the national health insurance scheme database to participate in The Australian Longitudinal Study of Women's Health. Self-reported data on back pain in the last 12 months, weight, physical activity and other socio-demographic factors were collected in 1998, 2001, 2004, 2007, 2010 and 2013. In 1998, 12,338 women completed the survey and 10,011 (74\%) completed the 2013 survey.

Results: At baseline, median (range) age was 49.5 (44.6 - 53.5) years and 54\% reported back pain. In multivariate analysis, baseline weight and depression were positive predictors of back pain over each 3 year survey interval and over the following 15 years, whereas participation in vigorous physical activity was protective. The effects of weight on back pain were most marked in women with a $\mathrm{BMI} \geq 25$.

Conclusions: Back pain is common in middle-aged women. Increased weight, weight gain and depression were independent predictors of back pain over 15 years, whereas participation in vigorous physical activity was protective. Targeting these lifestyle factors is an important area for future research on reducing the burden of back pain in middle-aged women. 


\section{Significance and Innovation}

- Back pain is common among middle-aged women.

- Increased weight, weight gain and depression were independent predictors of back pain over 15 years, whereas participation in vigorous physical activity was protective.

-Strategies to prevent back pain should focus on prevention of weight gain and depression; and promot and promotion of vigorous physical activity.
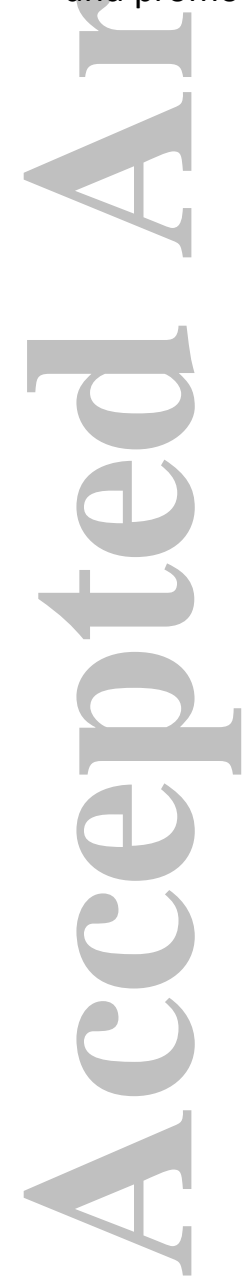

John Wiley \& Sons, Inc.

This article is protected by copyright. All rights reserved. 


\section{Introduction}

Back pain is a major public health issue, causing greater disability worldwide than any other condition (1). It is associated with a considerable financial burden (2) and substantial disability, as current treatment options have poor efficacy (3). Women are not only more likely to suffer from back pain (4-6), they are also more likely to utilise health care services to a greater extent than men $(7,8)$. In this context, understanding the predictors of back pain in women is vital to optimize preventive strategies. This is particularly important as past episodes of back pain predict recurrences over time $(9,10)$, and understanding risk factors associated with back pain will allow us to focus on prevention in women at high risk.

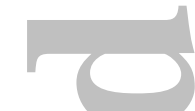

Previous studies of risk factors for back pain have largely been extracted from crosssectional studies (11-13); they suggest that weight, physical activity and depression are common risk factors for back pain $(11,14)$. However, there is inconsistency in the literature regarding the role of these risk factors on the prediction of future back pain, (15-17), and because most data are from working populations (18-20), with often lower rates of obesity than are seen in most developed countries (16).

Of the prospective studies that have assessed weight as a risk factor for back pain, only one has assessed back pain at more than one time point (21). That study found that obesity, but not overweight, was a predictor for persistent back pain. Similarly, while some cohort studies have demonstrated an association between physical inactivity and back pain $(15,22)$, 
other studies have yielded inconsistent results $(17,21,23-26)$. Moreover, while some systematic reviews have supported the notion that depression and psychological distress are potential predictors of back pain in women (27-29), another showed no relationship between work related psychosocial factors and back pain (30). Also, many of the prospective studies included in these reviews are limited by short duration, high rates of loss to follow up, small sample sizes and assessment of the exposure variables at a single time point $(11,14,15)$.

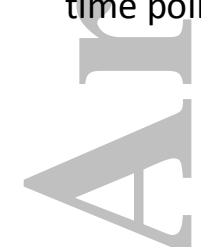

Although it is well-known that both obesity (16) and depression (31) are risk factors for back pain, interactions between these risks have received little research attention. For example, people who are both obese and depressed might be more susceptible to back pain and depression may increase suffering from back pain (32). Physical activity may also impact on both depression and weight, and therefore indirectly on back pain. To date few studies have examined these modifiable predictors of back pain in middle-aged women, with exposure and outcome measures assessed at multiple time points; hence major inconsistency and knowledge gaps persist in this area $(6,8,11-17)$.

The aim of this study was to determine whether modifiable factors, such as weight, depression and physical activity, predict back pain in middle-aged women in a large population-based cohort study conducted over a 15 year period. Based on the literature, we hypothesized that higher weight, lack of vigorous physical activity and the presence of depression would be predictors of future back pain in middle-aged women. Additionally, we 
hypothesized that the adverse effects of obesity on back pain would be heightened by a lack of participation in vigorous physical activity, or the presence of depression $(11,14,15)$.
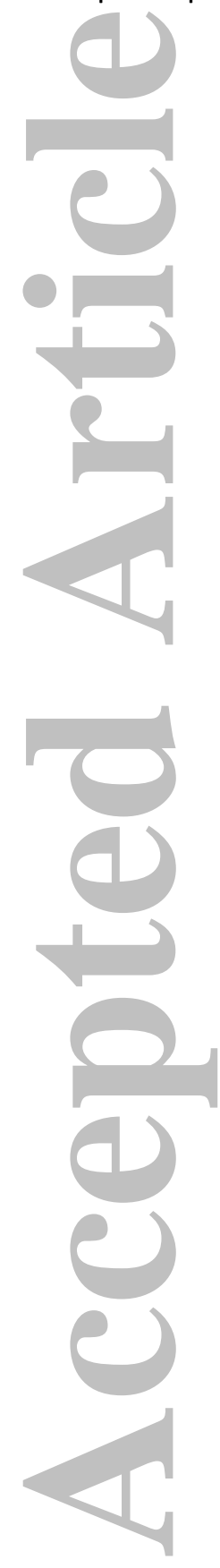

John Wiley \& Sons, Inc.

This article is protected by copyright. All rights reserved. 


\section{Patients and Methods}

Participants

The Australian Longitudinal Study of Women's Health (ALSWH) first collected mailed survey data from three age cohorts of Australian women in 1996 (young women 1973-1978;

middle-aged women 1946-1951; older women 1921-1926). Participants were selected at random from the national health insurance scheme (Medicare) database (which includes most permanent residents of Australia), with intentional oversampling from rural and remote regions $(33,34)$. Surveys included questions about a wide range of issues such as health behaviours, health service use and physical and mental health, as well as sociodemographic factors. The middle cohort, born 1946-1951, was surveyed in 1996, 1998, 2001, 2004, 2007, 2010 and 2013. The current study analysed data collected predominantly from the second survey in year 1998 (because important variables were available in this survey that were not included in the 1996 survey) through to the seventh survey in year 2013. Figure 1 shows the number of women who participated in the study, including those who answered a specific question on back pain. Further details of the methods used and cohort characteristics have been reported elsewhere $(33,34)$ and are available on the ALSWH website (www.alswh.org.au). The Human Research Ethics Committees of the University of Newcastle and the University of Queensland approved the study methods. Written informed consent was obtained from all participants.

\section{Back pain}

John Wiley \& Sons, Inc.

This article is protected by copyright. All rights reserved. 
At each survey, women were asked "In the last 12 months have you had back pain?" They were asked to circle one response which related to the frequency of their back pain: 'never', 'rarely', 'sometimes' or 'often'. Those who responded 'rarely' or 'never' having back pain were categorized as 'no back pain,' while those who responded 'sometimes' or 'often' were categorized as 'back pain'. They were also asked "Did you seek help for this problem?" Participants were asked to circle either 'Yes' or 'No'.

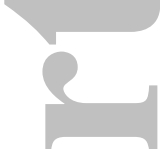

\section{Obesity}

Body mass index (BMI) was calculated at each survey from self-reported height and weight and classified as underweight or healthy $\left(\mathrm{BMI}<25 \mathrm{~kg} / \mathrm{m}^{2}\right.$ ); overweight (BMI 25.0-29.9 $\left.\mathrm{kg} / \mathrm{m}^{2}\right)$; or obese (BMI $\geq 30 \mathrm{~kg} / \mathrm{m}^{2}$ ) using the World Health Organization (WHO) criteria. Selfreported weight and height have previously been shown to be fairly accurate for the estimation of prevalence of overweight and obesity in middle-aged women (35).

\section{Physical activity}

Physical activity level was assessed using questions developed for the national surveillance of physical activity in Australia (36). Frequency and duration of brisk walking, moderateintensity and vigorous activity were used to calculate total physical activity in MET.minutes per week. Participants were instructed only to count activities lasting for at least 10 minutes. Physical activity was categorised based on total MET-minutes per week [none $(<40)$; low (40$<600)$; moderate (600-<1200); or high ( $\geq 1200)$ ] (36). Inadequate physical activity was determined to be less than $600 \mathrm{MET}$-minutes per week, the equivalent of 150 minutes per week of moderate-intensity physical activity, as per the Australian and US guidelines for 
women (37-39). Vigorous physical activity was defined as those who undertook any vigorous leisure physical activity based on the question "If you add up all the times you spent in each activity last week, how much time did you spend altogether doing vigorous physical activity (the ones that make you puff and pant, like vigorous aerobics, competitive sport, vigorous cycling, running, swimming)?" Participants reported time spent doing this type of physical activity and were categorised as either undertaking or not undertaking vigorous physical activity.

\section{Education and work}

Data on education status was collected only in the 1996 survey. Low education was classified as having either 'no formal qualifications' or 'School or Intermediate Certificate'. Data on workforce participation was collected at each survey, with questions such as "Which of the following describes your main occupation?" or "In the last week, how much time in total did you spend doing the following things?" Women were classified as either being 'in paid work' (i.e. full time, part time or casual paid work), or 'not in paid work' (i.e. studying, work without pay, looking for work, unpaid voluntary work, home duties, active leisure, passive leisure, socialising). Those in paid work were categorized as 'working one to 34 hours per week in paid work' or 'working 35 hours or greater per week in paid work'.

\section{Depression}

The presence or absence of depression in the 1998 survey was identified by the question "Have you ever been told by a doctor that you have depression?" Participants selected from the responses "Yes in the last 2 years", "Yes, more than 2 years ago" or the answer was left 
blank if the participant "never had this problem". In subsequent surveys (2001 onwards), the question "In the past three years, have you been diagnosed or treated for depression?" was asked, and participants answered yes if it applied to them.

\section{Smoking and menopausal status}

Smoking status was identified by the question "How often do you currently smoke cigarettes or any tobacco products?" Participants selected from the responses "Daily", "At least weekly", "Less often than weekly" or "Not at all". Those reported to be smoking daily, at least weekly or less often than weekly were categorised as smokers. Menopausal status was determined using the answers to several questions which asked women about gynaecological surgeries (oophorectomy, hysterectomy), hormonal replacement therapy, age of menopause and menstrual bleeding.

\section{Statistical analysis}

Chi-square tests were used to compare categorical variables in women with and without back pain; independent sample t tests were used to examine differences in continuous variables between these two groups. The predictors of interest in this study were weight, physical activity and depression; the other variables, age, height, employment status, menopause and smoking status, were included as potential confounders. In multivariate analyses we included variables if the relationship between the variable and the outcome was significant at $p \leq 0.1$ in univariate analysis, or had been shown in previous studies to be clinically significant. Generalized estimating equations (GEE) were used with logit link and exchangeable correlation structure to analyse the associations between risk factors such as 
weight (per $5 \mathrm{~kg}$ increments), weight gain (per $1.4 \mathrm{~kg}$, as the mean weight gain from survey 1 to 2), depression, age (per 5 years) and physical activity at baseline, with the risk of back pain at any time during the 15 year follow up period. Time lag analyses were also conducted using repeated measurements of the above risk factors at each survey and back pain reported one survey later $(40,41)$. All analyses, including interaction testing, were performed using two-sided tests and a significance level of less than $5 \%$ was considered statistically significant. All analyses were performed using Stata SE version 13.0 (StataCorp).
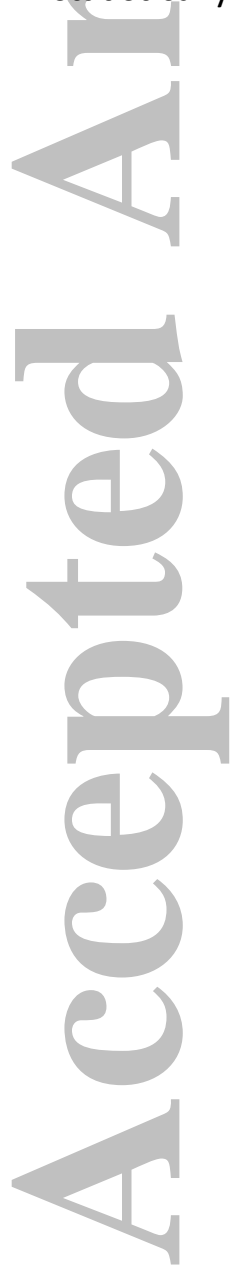

John Wiley \& Sons, Inc.

This article is protected by copyright. All rights reserved. 


\section{Results}

In 1998, 12,338 women participated in the study. Their median age was 49.5 years (range 44.6 to 53.3 years). After 15 years, $74 \%$ of these women completed the 2013 survey (Figure 1). The proportion of women who reported back pain at each of the six surveys is shown in Figure 2. Fifty four percent of women reported back pain at the first survey and $59.6 \%$ reported back pain in the final survey (Figure 2). Those with complete follow up at all surveys ( $n=7606)$ were of similar age (49.5 vs 49.5 years) and BMI $\left(26.1 \mathrm{vs} 26.3 \mathrm{~kg} / \mathrm{m}^{2}\right.$ ) at baseline, to those who completed only the baseline survey. The proportions who reported back pain $(52.3 \%$ vs $54.0 \%)$, depression ( $15.8 \%$ vs $17.7 \%$ ) and participation in inadequate levels of physical activity ( $28.0 \%$ vs $28.7 \%)$ were similar in these two groups.

Baseline characteristics of the participants in 1998 are shown in Table 1. Those who reported back pain were heavier, more likely to have been diagnosed with depression, more likely to be peri- or post-menopausal, a current smoker, and less likely to participate in vigorous leisure physical activity, than those who did not. However, the proportion doing inadequate levels of physical activity (<600 MET.mins/week) was not significantly different in these two groups. Those with back pain were also more likely to have a low level of education, less likely to be in paid work and less likely to be working more than 35 hours per week. Fifty-two percent of women with back pain reported seeking help for the condition at the first survey.

John Wiley \& Sons, Inc.

This article is protected by copyright. All rights reserved. 
Predictors of back pain over the following 15 years are presented in Table 2. In univariate models, baseline age, weight, weight gain and depression were associated with an increased risk of reporting back pain at any time over 15 years, whereas vigorous physical activity was associated with a lower risk of back pain. In multivariate models, for every $5 \mathrm{~kg}$ higher weight at the baseline survey, there was a $7 \%(95 \% \mathrm{Cl} 6 \%-8 \%)$ higher odds of back pain over the following 15 years, after adjustment for age, height, employment status, depression, vigorous physical activity, menopause and smoking status $(p<0.001)$. Women gained a mean of $1.4 \mathrm{~kg}$ (SD 6.0) between the baseline and second survey and a mean of $4.1 \mathrm{~kg}$ (SD 8.5 ) across the entire 15 year study period. For every $1.4 \mathrm{~kg}$ of weight gain from the baseline to the second survey, there was a $1 \%(95 \% \mathrm{Cl} 1 \%-2 \%)$ increased risk of back pain over the following 12 years. Participation in vigorous physical activity at baseline was associated with a $19 \%$ reduced risk of back pain, while being diagnosed with depression was associated with a $37 \%$ increased risk of back pain over the following 15 years, after adjustment for the above confounders including weight (both $p<0.001$ ).

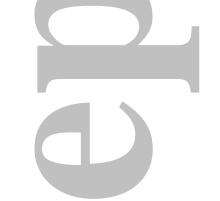

In addition, the effect of risk factors were examined using time lag analyses, whereby the measurement of the risk factors at each survey were related to back pain at the subsequent survey (approximately 3 years later) (Table 3 ). In multivariate analysis, for every $5 \mathrm{~kg}$ of weight, there was a $2 \%$ higher risk of back pain over each 3 year survey interval $(p<0.001)$. Participation in vigorous physical activity was associated with a $9 \%$ lower risk of back pain and depression was associated with a $23 \%$ higher risk of back pain over each survey interval, after adjustment for above confounders (both $\mathrm{p}<0.001$ ).

John Wiley \& Sons, Inc.

This article is protected by copyright. All rights reserved. 
The effects of weight and weight gain on back pain, stratified by BMI $<25 \mathrm{~kg} / \mathrm{m}^{2}$ and $\geq 25$ (ar) $\mathrm{kg} / \mathrm{m}^{2}$, are presented in Table 4. There was a consistently significant association between weight and back pain in overweight and obese women, but not in women with a healthy BMI. There was no evidence of an interaction between weight or weight gain and vigorous physical activity, weight or weight gain and depression and weight or weight gain and P menopausal status, on the risk of back pain (all $p>0.05$ for interactions).
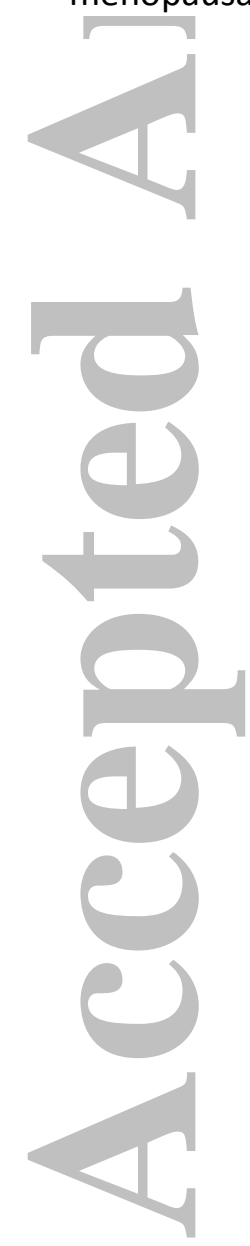

John Wiley \& Sons, Inc.

This article is protected by copyright. All rights reserved. 


\section{Discussion}

This large population-based cohort study of middle-aged Australian women demonstrated that self-reported back pain is common, with $54 \%$ of women reporting back pain at the baseline survey. In longitudinal analysis, baseline weight and depression were independent prec predictors of back pain over each 3 year survey interval and over the following 15 year period, whereas vigorous leisure time physical activity was protective. The mean weight gain was $1.4 \mathrm{~kg}$ from baseline to survey two and gaining $1.4 \mathrm{~kg}$ was also associated with an increased risk of back pain over the following 12 years. The effects of weight on back pain were not affected by participation in vigorous physical activity, being menopausal or depression status. However, the associations between weight and back pain were more consistent in those who were overweight or obese, than in those with healthy BMI.

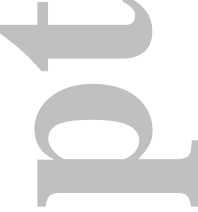

The 12 month prevalence is largely consistent with the high rates of back pain reported in large, community and population-based, cross-sectional studies from the UK, Turkey, Denmark and France, where the prevalence ranged from $40.9-57.2 \%$ for women of similar age (42-45). These data, together with our study, confirm that back pain is relatively common in middle-aged women living in Western countries.

In the current study, we found that weight was an independent predictor of back pain in middle-aged women over each 3 year survey interval and over the entire 15 year period. We 
also found that weight gain (which was on average $1.4 \mathrm{~kg}$ ) between baseline and survey two predicted back pain risk over the following 12 years. Most previous data assessing the relationship between weight and back pain have been from cross-sectional studies (11-13)

or selected working populations (18-20) and most only assessed back pain at one follow up point. For example in a Norwegian, prospective study of 25,450 community-based adults, baseline BMI in women was positively associated with incident back pain 11 years later (defined as pain persisting for at least 3 months continuously during the past year) (16). However, only $57 \%$ completed follow up at 11 years, with lower participation in those who were obese (16). There was also a lower rate of obesity in this cohort $(14.5-19.1 \%$ of women), than in many developed nations (approximately $30 \%$ for women in their 50s) (46).

In another Norwegian cohort study of 32,417 adults, using a similar definition of chronic back pain, BMI was associated with chronic back pain in women (15). However, there was no information in these studies about back pain in the intervening years. In another population-based study, persistent back pain (at three time points over 10 years) was predicted by obesity but not overweight (21). Whereas, this current ongoing study of a large sample of Australian community based women over multiple time points provides robust evidence that weight independently predicts future back pain risk in middle-aged women, in both the short and long term.

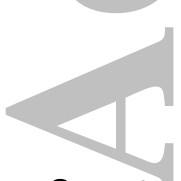

Our study also found that middle-aged women who participated in any vigorous leisure physical activity (defined as activities that make you 'puff and pant') had a decreased risk of back pain over each 3 year survey interval and over the following 15 years. The few prospective studies that have examined the relationship between physical activity and back 
pain in community-based populations have so far yielded inconsistent results $(17,24)$. In a large Norwegian study, women who did 1-1.9, but not 2 or more, exercise sessions per week had a lower risk of chronic back pain at 11 year follow-up, than those who did less than one exercise session per week (15). In another cohort study of 1836 adults with persistent back pain, the chance of recovery from back pain was greater for women who were physically active (22). In contrast, other cohort studies and systematic reviews have either found no significant association or conflicting evidence for an association between physical activity and back pain $(17,21,23-26)$. However, our large, population based study of women shows that any vigorous physical activity in middle-aged women is protective against the onset of back pain over the following 15 year period.

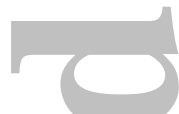

Depression also independently predicted back pain in middle-aged women over each 3 year survey interval and over 15 years. Depression and psychological distress have, in prospective studies, been previously shown to be predictors of back pain $(27,32,47,48)$. However, limitations in these studies have included small sample size, short duration of follow up and non-contemporaneous populations. Also, not all studies have shown consistent results. In a study of 2556 Belgian workers, women who felt depressed were not more likely to develop back pain over a 6 year period (49). However, data on psychological factors were only collected at baseline. Here we address these gaps in a large community based study over multiple time points, by showing that depression is an independent predictor of back pain in middle aged women over the following 15 years.

John Wiley \& Sons, Inc.

This article is protected by copyright. All rights reserved. 
The current study also demonstrated that the deleterious effects of weight on back pain were not affected by vigorous physical activity, being menopausal or depression status. Few longitudinal studies have sufficiently addressed these interactions and of those that have, exposure and outcome assessments were not performed at multiple time points, and one study evaluated only those with chronic back pain $(15,16)$. Our results support the importance of weight management in the prevention of back pain in mid-age women, as, most appear to be vulnerable to the adverse effects of weight gain. The predictive effects of weight gain persisted, despite the cohort gaining on average only $4.1 \mathrm{~kg}$ over 15 years.

Some limitations of our study were that weight was based on self-reported data at each time point. Although overweight and obese women are more likely to under-report their weight $(35,50)$, estimates of weight changes are unlikely to be affected, especially if the degree of under-reporting remains constant across surveys. However, under-reporting weight change is unlikely to explain the observed positive association, since it is more likely to bias the results toward the null, particularly in overweight and obese women.

While physical activity levels were also self-reported, the survey questions used have been found to have satisfactory validity when compared with accelerometry, and vigorous physical activity is reported more accurately (36). While there is a possibility that some participants over-estimated their participation in vigorous physical activity, it is most likely to cause non-differential misclassification and attenuate the findings towards the null. Although depression status was self-reported, similar questions have been found to be 
reasonably accurate when compared with psychiatric or psychological assessment (50). While back pain was self-reported, the question identified women with back pain that was sufficient to result in a high proportion of help-seeking and was associated with less likelihood of being in paid work. Whilst participants did not have a physician assessment or imaging to investigate the origin of their back pain, it is known that imaging does not correlate well with back pain symptoms and the majority of patients with back pain cannot be given an exact pathoanatomical diagnosis (51). Currently, recommendations are that investigations be generally performed if 'red flag' features are present, such as unexpected weight loss, fever or recent infection (52), but serious pathology among back pain sufferers in primary care is rare (52). Any potential misclassification where participants made an error in their reporting of back pain would be expected to cause non-differential misclassification, and attenuate our results. Although loss-to-follow-up in this 15 year study was low, it is possible that the sample has become less representative over time. However, there were no important differences in general characteristics and pain status between those who completed follow up and those who did not. A major strength of this study was the large, population-based sample, with relatively high participation rates over 15 years.

In summary, back pain was common in this large, longitudinal, community-based, middleaged female cohort. Weight and depression were independent predictors of back pain over each 3 year survey interval and over the following 15 year period. However, doing any vigorous leisure physical activity (defined as activities that make you 'puff and pant') significantly reduced back pain risk. We also found that weight-related back pain risk was 
not affected by participation in vigorous physical activity, being menopausal, or depression status, suggesting that all women appear to be vulnerable to the adverse effects of weight on back pain. Back pain is the leading cause of disability worldwide, thus even though the magnitude of the increased risk of back pain in this study was small, the significant burden of back pain on a population level means that these risk factors could potentially have a large impact. Despite the average weight gain in this cohort being only $4.1 \mathrm{~kg}$ over 15 years, there was a significant association between weight and back pain, suggesting that an emphasis on weight management may be important as a future prevention strategy. Although clinical intervention trials are required, strategies that target weight, lack of physical activity and mental health may be important in the prevention of back pain in middle-aged women.

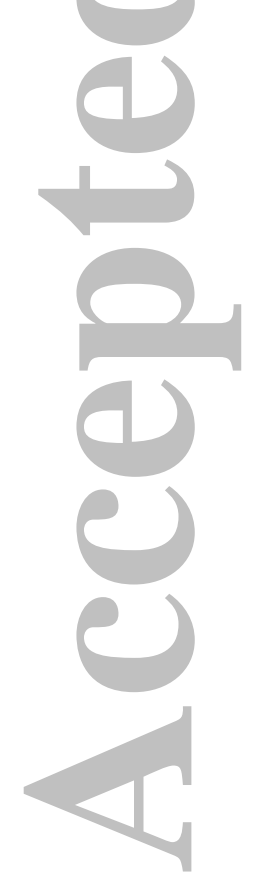

John Wiley \& Sons, Inc.

This article is protected by copyright. All rights reserved. 


\section{Author contributions}

S.R.E.B. was responsible for data analysis, writing the first draft, and editing the manuscript.

S.R.E.B. affirms that the manuscript is an honest, accurate, and transparent account of the study being reported; that no important aspects of the study have been omitted; and that any discrepancies from the study as planned have been explained. S.M.H. assisted in data analysis, editing and review of manuscript. W.J.B. was responsible for data collection and acquisition, contributed to study conception and the analysis plan, provided editing assistance and review of the manuscript. S.H. assisted with statistical analysis and manuscript editing. Y.W. assisted with editing and review of manuscript. H.T. contributed to study conception, provided editing assistance and review of the manuscript. D.M.U. $r($ covi provided editing assistance and review of the manuscript. F.M.C. contributed to study conception, data analysis, editing and review of manuscript. All authors gave final approval of the submitted version of the manuscript.

John Wiley \& Sons, Inc.

This article is protected by copyright. All rights reserved. 


\section{Acknowledgements}

S.R.E. Brady is supported by a National Health and Medical Research Council (NHMRC) Clinical Postgraduate Research scholarship (No. 1074979). S.M. Hussain is the recipient of the AFA-ARA Heald fellowship funded by Arthritis Australia Foundation. H. Teede is supported by an NHMRC Practitioner Fellowship 1942516. Y. Wang and D.M. Urquhart are the recipients of NHMRC Career Development Fellowships (Clinical Level 1 No. 1065464 and Clinical Level 1 No. 1011975, respectively).

The research on which this paper is based was conducted as part of the Australian Longitudinal Study on Women's Health, the University of Newcastle and the University of Queensland. We are grateful to the Australian Government Department of Health and Ageing for funding and to the women who provided survey data.

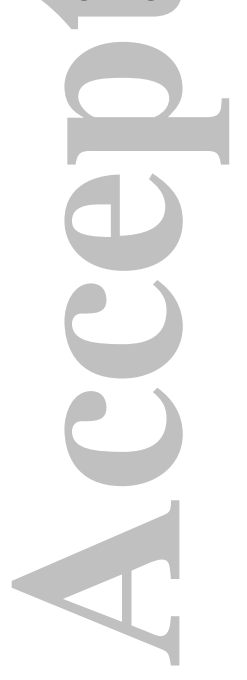

John Wiley \& Sons, Inc.

This article is protected by copyright. All rights reserved. 


\section{References}

1. Hoy D, March L, Brooks P, Blyth F, Woolf A, Bain C, et al. The global burden of low back pain: estimates from the Global Burden of Disease 2010 study. Annals of the rheumatic diseases. 2014;73(6):968-74.

2. Walker BF, Muller R, Grant WD. Low Back Pain in Australian Adults: The Economic Burden. Asia-Pacific Journal of Public Health. 2003;15(2):79-87.

3. Borenstein D. Mechanical low back pain--a rheumatologist's view. Nature reviews Rheumatology. 2013;9(11):643-53.

4. Fillingim RB, King CD, Ribeiro-Dasilva MC, Rahim-Williams B, Riley JL, 3rd. Sex, gender, and pain: a review of recent clinical and experimental findings. The journal of pain : official journal of the American Pain Society. 2009;10(5):447-85.

5. Leino PI, Berg MA, Puska P. Is back pain increasing? Results from national surveys in Finland during 1978/9-1992. Scand J Rheumatol. 1994;23(5):269-76.

6. Schneider S, Randoll D, Buchner M. Why do women have back pain more than men? A representative prevalence study in the federal republic of Germany. Clin J Pain. 2006;22(8):738-47.

7. Harreby M, Kjer J, Hesselsoe G, Neergaard K. Epidemiological aspects and risk factors for low back pain in 38-year-old men and women: a 25 -year prospective cohort study of 640 school children. European Spine Journal. 1996;5(5):312-8.

8. Walker BF, Muller R, Grant WD. Low back pain in Australian adults. health provider utilization and care seeking. Journal of Manipulative and Physiological Therapeutics. 2004;27(5):32735.

9. Hestbaek L, Leboeuf-Yde C, Engberg M, Lauritzen T, Bruun NH, Manniche C. The course of low back pain in a general population. results from a 5 -year prospective study. Journal of Manipulative and Physiological Therapeutics. 2003;26(4):213-9.

10. Hoy D, Brooks P, Blyth F, Buchbinder R. The Epidemiology of low back pain. Best practice \& research Clinical rheumatology. 2010;24(6):769-81.

11. Smuck M, Kao MC, Brar N, Martinez-Ith A, Choi J, Tomkins-Lane CC. Does physical activity influence the relationship between low back pain and obesity? The spine journal : official journal of the North American Spine Society. 2014;14(2):209-16.

12. Dario AB, Ferreira ML, Refshauge KM, Lima TS, Ordonana JR, Ferreira PH. The relationship between obesity, low back pain, and lumbar disc degeneration when genetics and the environment are considered: a systematic review of twin studies. The spine journal : official journal of the North American Spine Society. 2015;15(5):1106-17.

13. Shiri R, Karppinen J, Leino-Arjas P, Solovieva S, Viikari-Juntura E. The association between obesity and low back pain: a meta-analysis. American journal of epidemiology. 2010;171(2):135-54. 14. Chou L, Brady SR, Urquhart DM, Teichtahl AJ, Cicuttini FM, Pasco JA, et al. The Association Between Obesity and Low Back Pain and Disability Is Affected by Mood Disorders: A PopulationBased, Cross-Sectional Study of Men. Medicine. 2016;95(15):e3367.

15. Nilsen TI, Holtermann A, Mork PJ. Physical exercise, body mass index, and risk of chronic pain in the low back and neck/shoulders: longitudinal data from the Nord-Trondelag Health Study. American journal of epidemiology. 2011;174(3):267-73.

16. Heuch I, Heuch I, Hagen K, Zwart JA. Body mass index as a risk factor for developing chronic low back pain: a follow-up in the Nord-Trondelag Health Study. Spine. 2013;38(2):133-9.

17. Chen SM, Liu MF, Cook J, Bass S, Lo SK. Sedentary lifestyle as a risk factor for low back pain: a systematic review. International archives of occupational and environmental health. 2009;82(7):797806.

18. George SZ, Childs JD, Teyhen DS, Wu SS, Wright AC, Dugan JL, et al. Predictors of occurrence and severity of first time low back pain episodes: findings from a military inception cohort. PloS one. 2012;7(2):e30597. 
19. Jensen JN, Holtermann A, Clausen T, Mortensen OS, Carneiro IG, Andersen LL. The greatest risk for low-back pain among newly educated female health care workers; body weight or physical work load? BMC musculoskeletal disorders. 2012;13:87.

20. Leino-Arjas P, Solovieva S, Kirjonen J, Reunanen A, Riihimaki H. Cardiovascular risk factors and low-back pain in a long-term follow-up of industrial employees. Scand J Work Environ Health. 2006;32(1):12-9.

21. van Oostrom SH, Monique Verschuren WM, de Vet HC, Picavet HS. Ten year course of low back pain in an adult population-based cohort--the Doetinchem cohort study. European journal of pain. 2011;15(9):993-8.

22. Bohman T, Alfredsson L, Hallqvist J, Vingard E, Skillgate E. The influence of self-reported leisure time physical activity and the body mass index on recovery from persistent back pain among men and women: a population-based cohort study. BMC Public Health. 2013;13:385.

23. Shiri R, Solovieva S, Husgafvel-Pursiainen K, Telama R, Yang X, Viikari J, et al. The role of obesity and physical activity in non-specific and radiating low back pain: the Young Finns study. Seminars in arthritis and rheumatism. 2013;42(6):640-50.

24. Sitthipornvorakul E, Janwantanakul P, Purepong N, Pensri P, van der Beek AJ. The association between physical activity and neck and low back pain: a systematic review. European spine journal : official publication of the European Spine Society, the European Spinal Deformity Society, and the European Section of the Cervical Spine Research Society. 2011;20(5):677-89.

25. Croft PR, Papageorgiou AC, Thomas E, Macfarlane GJ, Silman AJ. Short-term physical risk factors for new episodes of low back pain. Prospective evidence from the South Manchester Back Pain Study. Spine. 1999;24(15):1556-61.

26. Picavet $\mathrm{H}$, Schuit A. Physical inactivity: a risk factor for low back pain in the general population? Journal of Epidemiology and Community Health. 2003;57(7):517-8.

27. Pincus T, Burton AK, Vogel S, Field AP. A systematic review of psychological factors as predictors of chronicity/disability in prospective cohorts of low back pain. Spine. 2002;27(5):E109-20.

28. Pinheiro MB, Ferreira ML, Refshauge K, Ordonana JR, Machado GC, Prado LR, et al.

Symptoms of Depression and Risk of New Episodes of Low Back Pain: A Systematic Review and Meta-Analysis. Arthritis care \& research. 2015;67(11):1591-603.

29. Pinheiro MB, Ferreira ML, Refshauge K, Maher CG, Ordonana JR, Andrade TB, et al. Symptoms of depression as a prognostic factor for low back pain: a systematic review. The spine journal : official journal of the North American Spine Society. 2016;16(1):105-16.

30. Hartvigsen J, Lings S, Leboeuf-Yde C, Bakketeig L. Psychosocial factors at work in relation to low back pain and consequences of low back pain; a systematic, critical review of prospective cohort studies. Occupational and Environmental Medicine. 2004;61(1):e2-e.

31. Luppino FS, de Wit LM, Bouvy PF, Stijnen T, Cuijpers P, Penninx BW, et al. Overweight, obesity, and depression: a systematic review and meta-analysis of longitudinal studies. Archives of general psychiatry. 2010;67(3):220-9.

32. Hauser W, Schmutzer G, Brahler E, Schiltenwolf M, Hilbert A. The impact of body weight and depression on low back pain in a representative population sample. Pain Med. 2014;15(8):1316-27.

33. Lee C, Dobson AJ, Brown WJ, Bryson L, Byles J, Warner-Smith P, et al. Cohort Profile: the Australian Longitudinal Study on Women's Health. Int J Epidemiol. 2005;34(5):987-91.

34. Brown WJ, Bryson L, Byles JE, Dobson AJ, Lee C, Mishra G, et al. Women's Health Australia: recruitment for a national longitudinal cohort study. Women Health. 1998;28(1):23-40.

35. Burton NW, Brown W, Dobson A. Accuracy of body mass index estimated from self-reported height and weight in mid-aged Australian women. Australian and New Zealand journal of public health. 2010;34(6):620-3.

36. Brown WJ, Burton NW, Marshall AL, Miller YD. Reliability and validity of a modified selfadministered version of the Active Australia physical activity survey in a sample of mid-age women. Australian and New Zealand journal of public health. 2008;32(6):535-41. 
37. Brown WJ, Bauman AE. Comparison of estimates of population levels of physical activity using two measures. Australian \& New Zealand Journal of Public Health. 2000;24(5):520-5.

38. Haskell WL, Lee IM, Pate RR, Powell KE, Blair SN, Franklin BA, et al. Physical activity and public health: updated recommendation for adults from the American College of Sports Medicine and the American Heart Association. Medicine and science in sports and exercise. 2007;39(8):142334.

39. Brown WJ, Bauman AE, Bull FC, Burton NW. Development of Evidence-based Physical Activity Recommendations for Adults (18-64 years). Report prepared for the Australian Government Department of Health; August, 2012.

40. van den Heuvel SG, Ariëns GAM, Boshuizen HC, Hoogendoorn WE, Bongers PM. Prognostic factors related to recurrent low-back pain and sickness absence. Scand J Work Environ Health. 2004;30(6):459-67.

41. Hoogendoorn WE, Bongers PM, de Vet HC, Twisk JW, van Mechelen W, Bouter LM. Comparison of two different approaches for the analysis of data from a prospective cohort study: an application to work related risk factors for low back pain. Occupational \& Environmental Medicine. 2002;59(7):459-65.

42. Hillman M, Wright A, Rajaratnam G, Tennant A, Chamberlain MA. Prevalence of low back pain in the community: implications for service provision in Bradford, UK. J Epidemiol Community Health. 1996;50(3):347-52.

43. Oksuz E. Prevalence, risk factors, and preference-based health states of low back pain in a Turkish population. Spine. 2006;31(25):E968-72.

44. Leboeuf-Yde C, Nielsen J, Kyvik KO, Fejer R, Hartvigsen J. Pain in the lumbar, thoracic or cervical regions: do age and gender matter? A population-based study of 34,902 Danish twins 20-71 years of age. BMC musculoskeletal disorders. 2009;10:39.

45. Gourmelen J, Chastang JF, Ozguler A, Lanoe JL, Ravaud JF, Leclerc A. Frequency of low back pain among men and women aged 30 to 64 years in France. Results of two national surveys. Annales de readaptation et de medecine physique : revue scientifique de la Societe francaise de reeducation fonctionnelle de readaptation et de medecine physique. 2007;50(8):640-4, 33-9.

46. Ng M, Fleming T, Robinson M, Thomson B, Graetz N, Margono C, et al. Global, regional, and national prevalence of overweight and obesity in children and adults during 1980-2013: a systematic analysis for the Global Burden of Disease Study 2013. The Lancet. 2014;384(9945):766-81.

47. Power C, Frank J, Hertzman C, Schierhout G, Li L. Predictors of low back pain onset in a prospective British study. Am J Public Health. 2001;91(10):1671-8.

48. Shaw WS, Means-Christensen AJ, Slater MA, Webster JS, Patterson TL, Grant I, et al. Psychiatric disorders and risk of transition to chronicity in men with first onset low back pain. Pain Med. 2010;11(9):1391-400.

49. Clays E, De Bacquer D, Leynen F, Kornitzer M, Kittel F, De Backer G. The impact of psychosocial factors on low back pain: longitudinal results from the Belstress study. Spine. 2007;32(2):262-8.

50. Sanchez-Villegas A, Schlatter J, Ortuno F, Lahortiga F, Pla J, Benito S, et al. Validity of a selfreported diagnosis of depression among participants in a cohort study using the Structured Clinical Interview for DSM-IV (SCID-I). BMC psychiatry. 2008;8:43.

51. Deyo RA, Weinstein JN. Low Back Pain. New England Journal of Medicine. 2001;344(5):363-

70.

52. Henschke N, Maher CG, Refshauge KM, Herbert RD, Cumming RG, Bleasel J, et al. Prevalence of and screening for serious spinal pathology in patients presenting to primary care settings with acute low back pain. Arthritis \& Rheumatism. 2009;60(10):3072-80. 
Figure 1: Numbers of women who answered the back pain question at each survey from
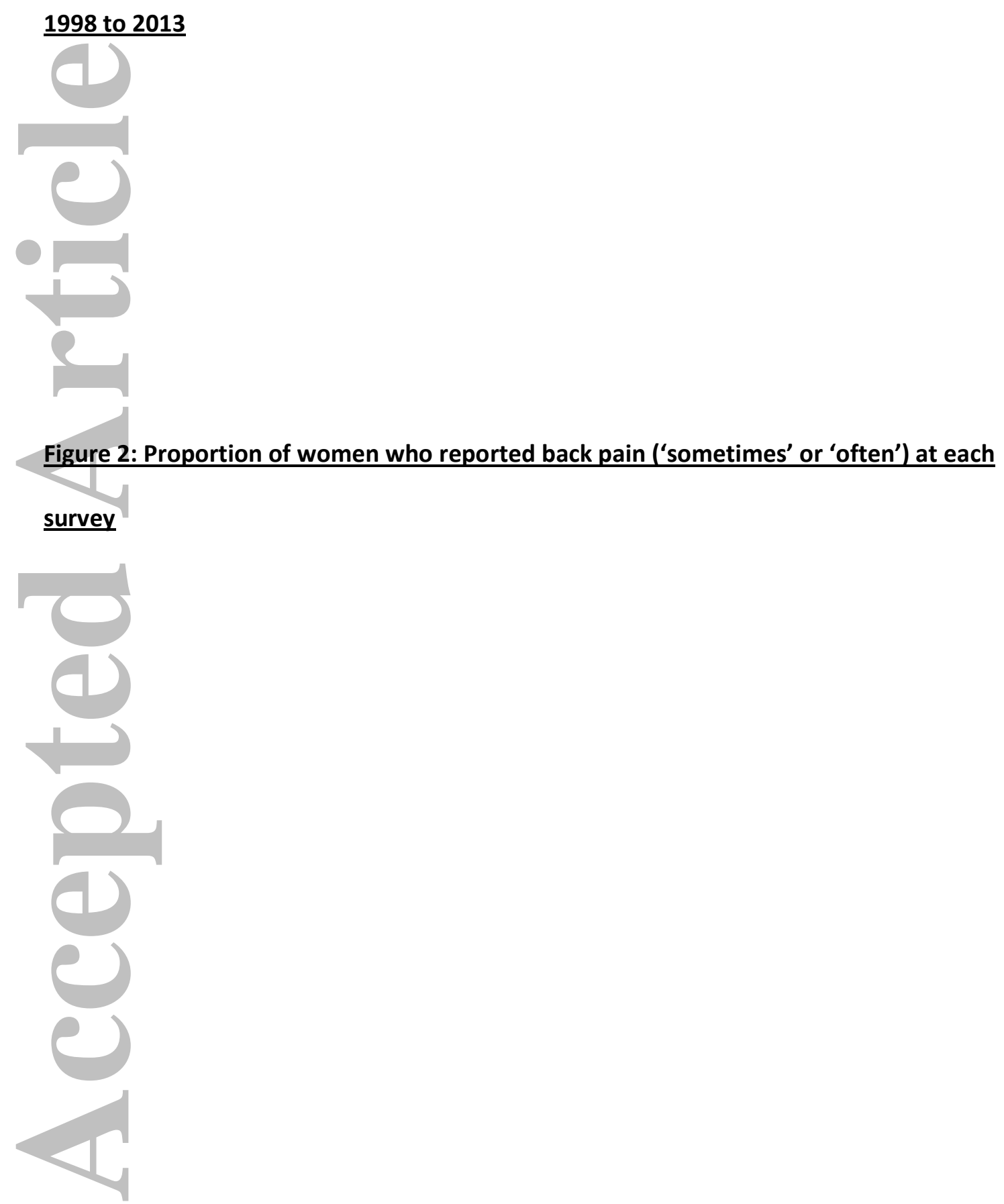

John Wiley \& Sons, Inc.

This article is protected by copyright. All rights reserved. 


\begin{tabular}{|c|c|}
\hline \multicolumn{2}{|c|}{ Response rate } \\
\hline Survey 1 (1998) - 12,338 answered survey (11,478 answered back pain question) & \multirow[t]{2}{*}{$100 \%$} \\
\hline - & \\
\hline Survey 2 (2001) - 11,226 answered survey ( 8,741 answered back pain question) & \multirow[t]{2}{*}{$91 \%$} \\
\hline 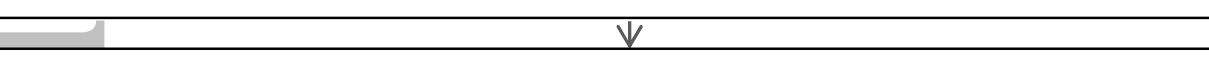 & \\
\hline Survey $3(2004)-10,905$ answered survey (10,530 answered back pain question) & \multirow[t]{2}{*}{$88 \%$} \\
\hline 2 & \\
\hline Survey 4 (2007) - 10,638 answered survey (10,492 answered back pain question) & \multirow[t]{2}{*}{$86 \%$} \\
\hline+1 & \\
\hline Survey 5 (2010) - 10,011 answered survey (9,891 answered back pain question) & \multirow[t]{2}{*}{$81 \%$} \\
\hline V & \\
\hline Survey 6 (2013) - 9151 answered survey (9,020 answered back pain question) & $74 \%$ \\
\hline
\end{tabular}

John Wiley \& Sons, Inc.

This article is protected by copyright. All rights reserved. 

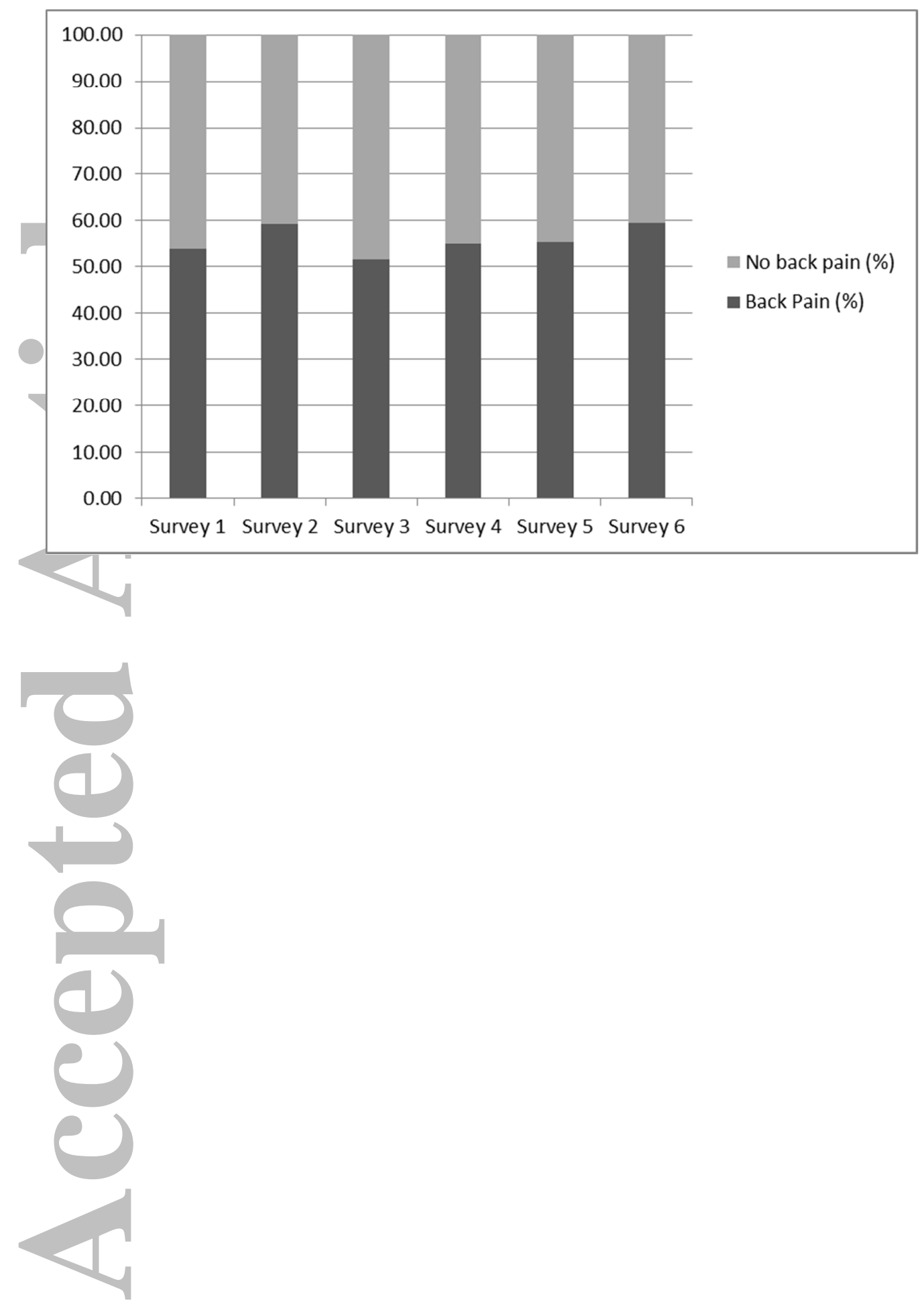

John Wiley \& Sons, Inc.

This article is protected by copyright. All rights reserved. 
Table 1: Characteristics of the women who did and did not report back pain ('sometimes'

\section{or 'often') at baseline in $1998(\mathrm{n}=11,478)$}

\begin{tabular}{|c|c|c|c|}
\hline & No back pain & Back pain & $P$ value \\
\hline Total number of participants, n (\%) & $5,286(46.1)$ & $6,192(54.0)$ & - \\
\hline Age (years), mean (SD) & $49.48(1.5)$ & $49.53(1.5)$ & 0.079 \\
\hline Weight (kg), mean (SD) & $68.40(13.7)$ & $71.11(15.2)$ & $<0.001$ \\
\hline Body mass index $\left(\mathrm{kg} / \mathrm{m}^{2}\right)$, mean $(\mathrm{SD})$ & $25.82(5.0)$ & $26.73(5.6)$ & $<0.001$ \\
\hline $\mathrm{BMI}<25 \mathrm{~kg} / \mathrm{m}^{2}, \mathrm{n}(\%)$ & $2,564(51.8)$ & $2,604(45.6)$ & \multirow{3}{*}{$<0.001$} \\
\hline Overweight (BMI $\left.25-<30 \mathrm{~kg} / \mathrm{m}^{2}\right), \mathrm{n}(\%)$ & $1,525(30.8)$ & $1,810(31.7)$ & \\
\hline Obese $\left(\mathrm{BMI} \geq 30 \mathrm{~kg} / \mathrm{m}^{2}\right), \mathrm{n}(\%)$ & $857(17.3)$ & $1,302(22.8)$ & \\
\hline Depression ever diagnosed by a doctor, $\mathrm{n}(\%)$ & $688(13.0)$ & $1,298(21.0)$ & $<0.001$ \\
\hline Peri- or post-menopausal, n (\%) & $2,779(52.6)$ & $3,538(57.2)$ & $<0.001$ \\
\hline Smoker, n (\%) & $816(15.5)$ & $1,130(18.4)$ & $<0.001$ \\
\hline \multicolumn{4}{|l|}{ Physical activity (MET.min/week), n (\%) } \\
\hline None $(<40)$ & 495 (9.9) & $686(11.7)$ & \multirow{4}{*}{0.003} \\
\hline $\operatorname{Low}(\geq 40,<600)$ & $914(18.3)$ & $1,015(17.4)$ & \\
\hline Moderate $(\geq 600,<1200)$ & $897(17.9)$ & $950(16.3)$ & \\
\hline $\operatorname{High}(\geq 1200)$ & $2,699(53.9)$ & $3,190(54.6)$ & \\
\hline Inadequate physical activity $(<600), \mathrm{n}(\%)$ & $1,409(28.2)$ & $1,701(29.1)$ & 0.266 \\
\hline $\begin{array}{l}\text { Participation in vigorous leisure physical activity, } \mathrm{n} \\
\text { (\%) }\end{array}$ & $995(19.3)$ & $868(14.5)$ & $<0.001$ \\
\hline $\begin{array}{l}\text { Low education status (intermediate certificate or } \\
\text { below), } \mathrm{n}(\%)^{*}\end{array}$ & 2,301 (43.9) & $3,232(52.6)$ & $<0.001$ \\
\hline \multicolumn{4}{|l|}{ Employment status, n (\%) } \\
\hline Not in paid work & $1,171(22.9)$ & $1,604(26.9)$ & \multirow{3}{*}{$<0.001$} \\
\hline Working 1-34 hours per week in paid work & $1,822(35.6)$ & $2,195(36.8)$ & \\
\hline Working $\geq 35$ hours per week in paid work & $2,125(41.5)$ & $2,168(36.3)$ & \\
\hline Proportion seeking help for back pain, $\mathrm{n}(\%)$ & $388(8.3)$ & $2,711(52.0)$ & $<0.001$ \\
\hline
\end{tabular}



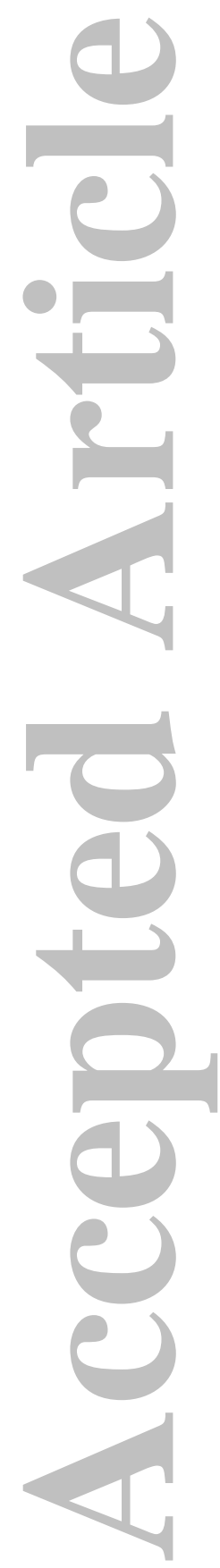

John Wiley \& Sons, Inc.

This article is protected by copyright. All rights reserved. 
Table 2: Risk factors for back pain over 15 years - GEE models using risk factors from baseline survey and report of back pain at any survey

\begin{tabular}{|c|c|c|c|c|}
\hline & $\begin{array}{l}\text { Univariate } \\
\text { Odds ratio }(95 \% \mathrm{Cl})\end{array}$ & P value & $\begin{array}{l}\text { Multivariate } \\
\text { Odds ratio }(95 \% \mathrm{Cl})^{\mathrm{a}}\end{array}$ & P value \\
\hline Age at baseline (per 5 year increase) & $1.06(1.05-1.08)$ & $<0.001$ & $1.01(0.99-1.03)$ & 0.225 \\
\hline Weight (per $5 \mathrm{~kg}$ ) at baseline & $1.07(1.06-1.08)$ & $<0.001$ & $1.07(1.06-1.08)$ & $<0.001$ \\
\hline $\begin{array}{l}\text { Weight gain (per } 1.4 \mathrm{~kg} \text { ) from baseline to the second } \\
\text { survey* }\end{array}$ & $1.01(1.00-1.01)$ & $<0.001$ & $1.01(1.01-1.02)$ & $<0.001$ \\
\hline Vigorous leisure physical activity at baseline & $0.81(0.78-0.85)$ & $<0.001$ & $0.81(0.78-0.85)$ & $<0.001$ \\
\hline Depression at baseline & $1.35(1.28-1.41)$ & $<0.001$ & $1.37(1.29-1.45)$ & $<0.001$ \\
\hline \multicolumn{5}{|c|}{$\begin{array}{l}{ }^{a} \text { Multivariate analysis adjusted for age, weight, height, employment status, depression, vigorous physical activity, menopausal anc } \\
\text { smoking status at baseline. } \\
{ }^{*} \text { Average weight gain in this population }\end{array}$} \\
\hline
\end{tabular}




\section{Table 3: Risk factors for back pain - time lagged GEE models using explanatory and outcome variables over each 3 year survey interval}

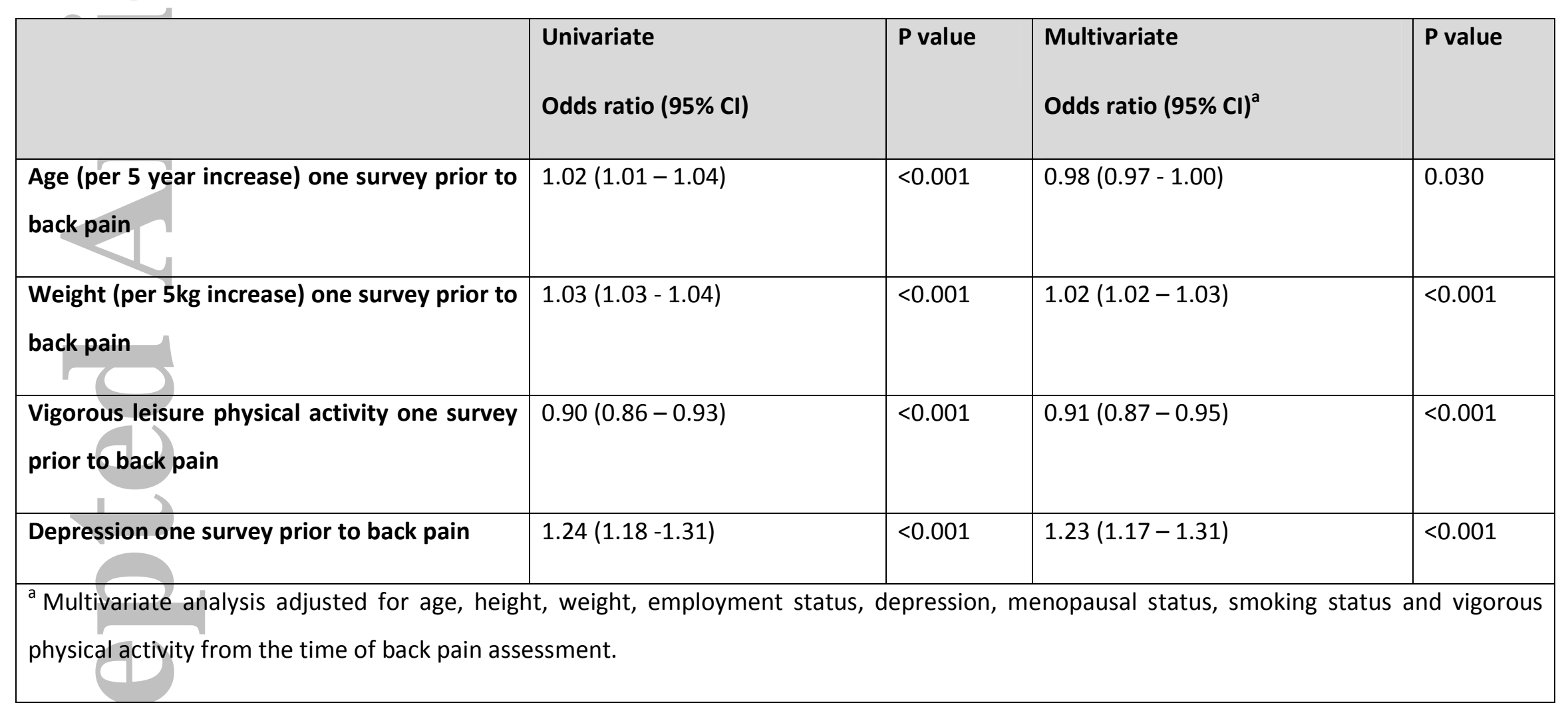


Table 4: Associations between weight and back pain, stratified by BMI

\begin{tabular}{|c|c|c|c|c|}
\hline & \multicolumn{2}{|c|}{$\mathrm{BMI}<25 \mathrm{~kg} / \mathrm{m}^{2}$} & \multicolumn{2}{|l|}{$\mathrm{BMI} \geq 25 \mathrm{~kg} / \mathrm{m}^{2}$} \\
\hline & Multivariate OR (95\% CI) & $P$ value & Multivariate OR (95\% Cl) & $P$ value \\
\hline Weight (per $5 \mathrm{~kg}$ ) at baseline & $1.07(1.03-1.10)$ & $<0.001$ & $1.06(1.05-1.08)$ & $<0.001$ \\
\hline Weight gain (per $1.4 \mathrm{~kg}$ ) at baseline* & $1.01(1.00-1.01)$ & 0.234 & $1.01(1.00-1.01)$ & 0.003 \\
\hline Weight (per $5 \mathrm{~kg}$ ) one survey prior to back pain & $1.00(0.98-1.01)$ & 0.574 & $1.02(1.01-1.03)$ & $<0.001$ \\
\hline \multicolumn{5}{|c|}{$\begin{array}{l}\text { All multivariate analyses were adjusted for age, height, depression, vigorous physical activity, employment status, smoking and } \\
\text { menopause status. } \\
\text { *Average weight gain in this population }\end{array}$} \\
\hline
\end{tabular}

John Wiley \& Sons, Inc.

This article is protected by copyright. All rights reserved. 
STROBE Statement — checklist of items that should be included in reports of observational studies

\begin{tabular}{|c|c|c|}
\hline & $\begin{array}{l}\text { Page } \\
\text { No(s) }\end{array}$ & Recommendation \\
\hline \multirow[t]{2}{*}{ Title and abstract } & \multirow[t]{2}{*}{$2-4$} & $\begin{array}{l}\text { (a) Indicate the study's design with a commonly used term in the title or the } \\
\text { abstract }\end{array}$ \\
\hline & & $\begin{array}{l}\text { (b) Provide in the abstract an informative and balanced summary of what was done } \\
\text { and what was found }\end{array}$ \\
\hline \multicolumn{3}{|l|}{ Introduction } \\
\hline Background/rationale & $6-8$ & Explain the scientific background and rationale for the investigation being reported \\
\hline Objectives & $7-8$ & State specific objectives, including any prespecified hypotheses \\
\hline \multicolumn{3}{|l|}{ Methods } \\
\hline Study design & 9 & Present key elements of study design early in the paper \\
\hline Setting & 9 & $\begin{array}{l}\text { Describe the setting, locations, and relevant dates, including periods of } \\
\text { recruitment, exposure, follow-up, and data collection }\end{array}$ \\
\hline \multirow[t]{3}{*}{ Participants } & \multirow[t]{3}{*}{9} & $\begin{array}{l}\text { (a) Cohort study-Give the eligibility criteria, and the sources and methods of } \\
\text { selection of participants. Describe methods of follow-up } \\
\text { Case-control study-Give the eligibility criteria, and the sources and methods of } \\
\text { case ascertainment and control selection. Give the rationale for the choice of cases } \\
\text { and controls }\end{array}$ \\
\hline & & $\begin{array}{l}\text { Cross-sectional study - Give the eligibility criteria, and the sources and methods } \\
\text { of selection of participants }\end{array}$ \\
\hline & & $\begin{array}{l}\text { (b) Cohort study_-For matched studies, give matching criteria and number of } \\
\text { exposed and unexposed } \\
\text { Case-control study-For matched studies, give matching criteria and the number } \\
\text { of controls per case }\end{array}$ \\
\hline Varis & $10-12$ & $\begin{array}{l}\text { Clearly define all outcomes, exposures, predictors, potential confounders, and } \\
\text { effect modifiers. Give diagnostic criteria, if applicable }\end{array}$ \\
\hline $\begin{array}{l}\text { Data } \\
\text { meas }\end{array}$ & $10-12$ & $\begin{array}{l}\text { For each variable of interest, give sources of data and details of methods of } \\
\text { assessment (measurement). Describe comparability of assessment methods if there } \\
\text { is more than one group }\end{array}$ \\
\hline Bias & $10-12$ & Describe any efforts to address potential sources of bias \\
\hline Study & 9 & Explain how the study size was arrived at \\
\hline Quantitative variables & $10-12$ & $\begin{array}{l}\text { Explain how quantitative variables were handled in the analyses. If applicable, } \\
\text { describe which groupings were chosen and why }\end{array}$ \\
\hline \multirow[t]{7}{*}{ Statistical methods } & \multirow[t]{7}{*}{$12-13$} & $\begin{array}{l}\text { (a) Describe all statistical methods, including those used to control for } \\
\text { confounding }\end{array}$ \\
\hline & & (b) Describe any methods used to examine subgroups and interactions \\
\hline & & (c) Explain how missing data were addressed \\
\hline & & (d) Cohort study - If applicable, explain how loss to follow-up was addressed \\
\hline & & Case-control study - If applicable, explain how matching of cases and controls \\
\hline & & was addressed \\
\hline & & $\begin{array}{l}\text { Cross-sectional study-If applicable, describe analytical methods taking account } \\
\text { of sampling strategy }\end{array}$ \\
\hline
\end{tabular}

(e) Describe any sensitivity analyses

Continued on next page 


\begin{tabular}{|c|c|c|}
\hline \multicolumn{3}{|l|}{ Results } \\
\hline \multirow[t]{3}{*}{ Participants } & \multirow[t]{3}{*}{$\begin{array}{l}9 \\
14\end{array}$} & $\begin{array}{l}\text { (a) Report numbers of individuals at each stage of study - eg numbers potentially eligible, } \\
\text { examined for eligibility, confirmed eligible, included in the study, completing follow-up, and } \\
\text { analysed }\end{array}$ \\
\hline & & (b) Give reasons for non-participation at each stage \\
\hline & & (c) Consider use of a flow diagram \\
\hline \multirow{4}{*}{$\begin{array}{l}\text { Descriptive } \\
\text { data }\end{array}$} & \multirow[t]{4}{*}{14} & (a) Give characteristics of study participants (eg demographic, clinical, social) and \\
\hline & & information on exposures and potential confounders \\
\hline & & (b) Indicate number of participants with missing data for each variable of interest \\
\hline & & (c) Cohort study-Summarise follow-up time (eg, average and total amount) \\
\hline \multirow{3}{*}{ Outcome data } & \multirow[t]{3}{*}{14} & Cohort study_Report numbers of outcome events or summary measures over time \\
\hline & & $\begin{array}{l}\text { Case-control study-Report numbers in each exposure category, or summary measures of } \\
\text { exposure }\end{array}$ \\
\hline & & Cross-sectional study_Report numbers of outcome events or summary measures \\
\hline \multirow[t]{3}{*}{ Main results } & \multirow[t]{3}{*}{$\begin{array}{l}15- \\
16\end{array}$} & $\begin{array}{l}\text { (a) Give unadjusted estimates and, if applicable, confounder-adjusted estimates and their } \\
\text { precision (eg, } 95 \% \text { confidence interval). Make clear which confounders were adjusted for and } \\
\text { why they were included }\end{array}$ \\
\hline & & (b) Report category boundaries when continuous variables were categorized \\
\hline & & $\begin{array}{l}\text { (c) If relevant, consider translating estimates of relative risk into absolute risk for a } \\
\text { meaningful time period }\end{array}$ \\
\hline nalyses & 16 & $\begin{array}{l}\text { Report other analyses done-eg analyses of subgroups and interactions, and sensitivity } \\
\text { analyses }\end{array}$ \\
\hline \multicolumn{3}{|l|}{ Discussion } \\
\hline Key results & 17 & Summarise key results with reference to study objectives \\
\hline Limitations & $\begin{array}{c}20- \\
21\end{array}$ & $\begin{array}{l}\text { Discuss limitations of the study, taking into account sources of potential bias or imprecision. } \\
\text { Discuss both direction and magnitude of any potential bias }\end{array}$ \\
\hline Interpretation & $\begin{array}{c}21- \\
22\end{array}$ & $\begin{array}{l}\text { Give a cautious overall interpretation of results considering objectives, limitations, } \\
\text { multiplicity of analyses, results from similar studies, and other relevant evidence }\end{array}$ \\
\hline Generalisability & 22 & Discuss the generalisability (external validity) of the study results \\
\hline
\end{tabular}

Funding $24 \begin{aligned} & \text { Give the source of funding and the role of the funders for the present study and, if applicable, } \\ & \text { for the original study on which the present article is based }\end{aligned}$

Note: An Explanation and Elaboration article discusses each checklist item and gives methodological background and published examples of transparent reporting. The STROBE checklist is best used in conjunction with this article (freely available on the Web sites of PLoS Medicine at http://www.plosmedicine.org/, Annals of Internal Medicine at http://www.annals.org/, and Epidemiology at http://www.epidem.com/). Information on the STROBE Initiative is available at www.strobe-statement.org. 


\section{University Library}

\section{- M M N E R VA A gateway to Melbourne's research publications}

Minerva Access is the Institutional Repository of The University of Melbourne

Author/s:

Brady, SRE;Hussain, SM;Brown, WJ;Heritier, S;Wang, Y;Teede, H;Urquhart, DM;Cicuttini, FM

Title:

Predictors of Back Pain in Middle-Aged Women: Data From the Australian Longitudinal Study of Women's Health

Date:

2017-05-01

Citation:

Brady, S. R. E., Hussain, S. M., Brown, W. J., Heritier, S., Wang, Y., Teede, H., Urquhart, D. M. \& Cicuttini, F. M. (2017). Predictors of Back Pain in Middle-Aged Women: Data From the Australian Longitudinal Study of Women's Health. ARTHRITIS CARE \& RESEARCH, 69 (5), pp.709-716. https://doi.org/10.1002/acr.22982.

Persistent Link:

http://hdl.handle.net/11343/292811 